\title{
Prevalence and Associated Factors of Hypertension among Civil Servants Working in Arba Minch Town, South Ethiopia
}

\author{
Aschenaki Kalssa ${ }^{1}$, Gistane Ayele ${ }^{2}$, Alemu Tamiso ${ }^{3}$, Tadele Girum ${ }^{4}$ \\ ${ }^{1}$ Federal Ministry of Health, National Institute for Tsetse and Trypanosomiasis Eradication Project, Arba Minch, Ethiopia \\ ${ }^{2,3}$ Department of Public health, College of Medicine and Health Sciences, Arba Minch University, Arba Minch, Ethiopia \\ ${ }^{4}$ Department of Public health, College of Medicine and Health Sciences, Wolkite University, Wolkite, Ethiopia
}

\begin{tabular}{l} 
Article Info \\
\hline Article history: \\
Received Aug 8, 2016 \\
Revised Oct 20, 2016 \\
Accepted Nov 16, 2016 \\
\hline
\end{tabular}

\section{Keyword:}

Arba minch

Civil servants

Hypertension

Prevalence

Risk factors

\begin{abstract}
Despite Hypertension is a global public health challenge and a leading modifiable risk factor for cardiovascular disease and death attention was not given in developing countries. Therefore measuring the prevalence and identifying predictors of Hypertension is very important. Institution based cross sectional study design was employed from March-April, 2016 by taking 319 randomly selected civil servants working in in Arba Minch town. Data was collected using structured questionnaire and standardized instruments for physical examination by 5 trained nurses. SPSS version 20 was used for data analysis. Bi-variable and Multivariate logistic regression was employed for analysis of risk factors. The mean SBP and DBP of study participants were $120.87 \pm 14.15 \mathrm{mmHg}$ and $80.28 \pm 8.8 \mathrm{mmHg}$, respectively. The prevalence of hypertension was found to be $27.8 \%$ $(95 \% \mathrm{CI}=22.9-32.7 \%)$. Civil servants of age 50 years and above [AOR $=13.3$, age 40-49 years $[\mathrm{AOR}=5$,], age 30-39 years $[\mathrm{AOR}=3.5]$, abdominal obesity $[\mathrm{AOR}=12.2]$, general obesity $[\mathrm{AOR}=4.2]$, stress status [AOR $=12.3]$, current alcohol drink $[\mathrm{AOR}=3.3]$, ex-drinker $[\mathrm{AOR}=8.9]$ and family history of hypertension [AOR $=5.6$ ] were found to be significantly associated with hypertension. The prevalence indicates that it is hidden epidemic in this population; therefore for screening and risk reduction program are needed.
\end{abstract}

Copyright $\odot 2016$ Institute of Advanced Engineering and Science. All rights reserved.

\section{Corresponding Author:}

Tadele Girum,

Department of Public Health,

College of Medicine and Health Sciences,

Wolkite University,

Wolkite City, Ethiopia.

Email: girumtadele@yahoo.com

\section{INTRODUCTION}

Hypertension commonly referred to as high blood pressure and can be defined as systolic blood pressure of $140 \mathrm{mmHg}$ or greater, and or diastolic blood pressure of $90 \mathrm{mmHg}$ or greater, or the use of antihypertensive drug or being told at least twice by a physician or other health professional that one has high blood pressure [1]. It can be essential (without known cause); accounts for $90-95 \%$ or secondary hypertension (due to disease condition) [2]. For the Majority of cases the cause is unknown; however, there are certain risk factors. Modifiable risk factors include body weight, salt intake, alcohol intake, physically inactive, psychosocial stressors, socio-demographic status, diet, smoking and exposure to environmental tobacco smoke and Non modifiable risk factors include age, gender, ethnicity/race and family history [3].

Hypertension is a global public health challenge and a leading modifiable risk factor for cardio-vascular disease (CVD) and death. According to the global health observatory report, the overall prevalence of hypertension in adult age 25 and above was around $40 \%$ and estimated to cause 7.5 million 
deaths, about $12.8 \%$ of the total of all death worldwide. The prevalence varies across different income categories with 35\% in high income countries and $40 \%$ in low, lower-middle and upper-middle income countries [2]; where the highest prevalence is in South Africa (77.9\%) and the lowest in India with the overall prevalence of $5.29 \%$ [4].

Hypertension is a common public health challenge in the region of Africa with prevalence data varies from areas to area. Current disease estimates for Sub-Saharan Africa indicate that there is a wide disparity (6 to 48\%) in the prevalence of hypertension [5]. Hypertension is one of the most frequently Observed risk factor for CVD in both rural and urban community of the region with age standardized Prevalence rate of $19.3 \%$ and $21.4 \%$ in rural Nigeria and Kenya respectively and $23.7 \%$ and $38 \%$ in urban Tanzania and Namibia [6].

In Ethiopia, several studies from the last decade showed that the prevalence of CVD risk factor increased rapidly [7]. A study conducted in Dabat district and Gondor town of North West Ethiopia indicated that the overall prevalence of hypertension was $27.9 \%$ with the proportion in the urban and rural resident being $30.7 \%$ and $25.3 \%$ respectively [8]. Another community based study in southern region of Durame town and Sidama Zone visualized that the overall prevalence of $22.4 \%$ and $9.9 \%$ respectively [9-10].

Hypertension is an emerging disease of developing countries like Ethiopia; however the health delivery system basically focus on emergencies and infectious disease and health workers lacks sufficient training in non-communicable disease (NCD) management [11]. Despite the increment of patient attendance and medical admission related to hypertension in major hospitals of our country, there is no organized data on the prevalence and associated factors and efforts has not been paid by health care practitioners and policy makers on the prevention of the risk factors. There for knowing the magnitude and understanding the risk factors are important for effective preventative activities to be brought about.

\section{MATERIALS AND METHODS}

\subsection{Study Design and Settings}

This cross-sectional study was conducted from March to April, 2016 in Arba Minch Town; the capital of Gamo Gofa Zone, southern Ethiopia. It is located at $505 \mathrm{Km}$ south of Addis Ababa near to Lake Abaya. The town is organized by four sub-cities and eleven kebeles having a total population of 74843 of which 5874 are civil servants. There are five federal institutes, six regional institutes, twenty zonal institutes, eighteen Arba Minch town institutes and twenty Arba Minch zuria institutes.

\subsection{Study Population and Sampling Technique}

The source population of this study was all civil servants working in Arba Minch town. The sample size was determined on the basis of previous studies done in Ethiopia for hypertension. Then using single population proportion formula; by taking prevalence of hypertension as $27.3 \%$ [12]; 5\% marginal of error; $95 \%$ CI; the sample size was 305. Since the total number of target population is less than 10,000 (5874), reduction formula was applied. Therefore using the reduction formula and $10 \%$ nonresponse rate the total calculated sample size was 319 . The sample size calculated for the second objective with double population proportion formula was only 136; therefore the sample size obtained for the first objective was enough to answer the second objective as well.

Sampling procedure: government institutions hosted in Arba Minch town are categorized in to federal (5), regional (6), zonal (20), Arba Minch town (18) and Arba Minch zuria (20). Simple random sampling by using lottery method was used to select $30 \%$ of departments. Civil servants lists were obtained from the human resource core process of the selected institute then participants were randomly and proportionally selected from the list. On the way pregnant women were excluded to rule out pregnancy induced hypertension.

\subsection{Data Collection Procedure and Data Quality Control}

The source of data for the study was individual participant's history and physical examination findings. Data was collected by using: check list and standardized instruments

a. Structured Questionnaires: It was brought about in accordance with the STEP wise approach of the WHO for NCD surveillance in developing countries. A STEP is a sequential process involving the collection of data on selected risk factors [13].

b. Anthropometric measurements: height, weight, waist circumference and Hip circumference were measured after completing the interview, with a standard and calibrated instrument In accordance with the WHO guideline [13].

c. Blood pressure (BP) measurement: BP was measured by using a standard measuring device with the participant sitting after resting for at least 5 minutes. BP was measured three times, with at least three 
minutes between consecutive measurements. In accordance with the WHO recommendation the mean SBP and DBP from the second and third measurements were considered for analysis [13].

d. Data quality management: Validity was maintained by Using standardized questionnaire that was properly developed from review of published articles and WHO Step wise approach for surveillance of NCD in developing countries, Proper training of the interviewers on data collection procedures, proper categorization and coding of the questionnaires and $10 \%$ of the completed questionnaire was reviewed and checked for completeness and relevance every day by principal investigator. Reliability of the questionnaire was checked by pretesting of the tool on 5\% the study subjects from institutes other than selected and measuring of blood pressure, height and weight were taken twice and an average of the two reading were recorded.

e. Data collectors: Five nurses with substantial experience in data collection were participated after they were trained for about a days on contents of questionnaires, data collection techniques and on ethical conduct of human research.

\subsection{Study Variables and Data Analysis}

The Dependent variables was prevalence of systemic hypertension while the independent variables were Socio demographic factors (age, sex, working category, education, religion, ethnicity, marital status), Cognitive and Affection factors (knowledge and perception of hypertension), Behavioral factors (physical activities, smoking, diet habits, alcohol consumption, stress status and khat chewing) and Bio-medical factors (nutritional status, family history of hypertension family history of diabetes mellitus, history of diabetes mellitus).

After data collection, each questionnaire was checked for completeness and consistency. Data was cleaned, coded and entered into Epi-info version 7 and exported to SPSS version 20 for Windows, then Exploratory data analysis carried out to check the levels of missing values, presence of influential outliers, independence of errors, multi-collinearity and normality. Binary and multiple logistic regressions were run to assess the association of various factors with hypertension. The fitness of the model was checked by Hosmer and Lemeshow test. The results were presented in the form of tables, texts and figure. The strength of association of predictor variables with hypertension were assessed using odds ratio and significance of variables were reported by using $95 \%$ confidence interval and $p$-values $<0.05$.

\subsection{Ethical Consideration}

Ethical clearance was obtained from institutional review office of Arba Minch University. Permission to conduct the study also was obtained from town administration selected institutes. Informed consent was obtained from each study participants. Each respondents were informed about the purpose of the study and also that all data obtained from them were kept confidential by using codes instead of any personal identifiers. Hypertensive cases diagnosed during survey were given advice about preventative issues and linked to health institute for further diagnosis and treatment.

\section{RESULTS AND DISCUSSION}

\subsection{Participants' Characteristics}

\subsubsection{Socio-Demographic and Economic Characteristic of Participants}

A total of 306 participants took part in this study with a response rate of $95.9 \%$. One hundred seventy eight (58.2\%) participants were male and $128(41.8 \%)$ were females. Age of respondents varied from 20-61 years with the mean age of 37.22 (SD 9.7). Two hundred twenty four $(73.2 \%)$ participants were married. About $59.5 \%$ of respondents were firs degree holders and $170(55.6 \%)$ were technical professionals (Table 1). 
Table 1. Socio-Demographic Character of Civil Servants Working in A/Minch Town, 2016

\begin{tabular}{|c|c|c|c|}
\hline \multirow{2}{*}{ Variables } & \multicolumn{2}{|c|}{ Frequency } & \multirow{2}{*}{ Overall $n=306$} \\
\hline & Male $=$ no $(\%)$ & Female $=$ no $(\%)$ & \\
\hline \multicolumn{4}{|l|}{ Marital status } \\
\hline single & $59(81.9 \%)$ & $13(18.1 \%)$ & $72(23.5 \%)$ \\
\hline married & $113(50.4 \%)$ & $111(49.6 \%)$ & $224(73.2 \%)$ \\
\hline Divorce \& widowed & $6(60 \%)$ & $4(40 \%)$ & $10(3.3 \%)$ \\
\hline \multicolumn{4}{|l|}{ Education } \\
\hline$\leq 12$ grade & $16(55.2 \%)$ & $13(44.8 \%)$ & $29(9.5 \%)$ \\
\hline Certificate & $7(30.4 \%)$ & $16(69.6 \%)$ & $23(7.5 \%)$ \\
\hline Diploma & $29(40.3 \%)$ & $43(59.7 \%)$ & $72(23.5 \%)$ \\
\hline Degree \& above & $126(69.2 \%)$ & $56(30.8 \%)$ & $182(59.5 \%)$ \\
\hline \multicolumn{4}{|l|}{ Working category } \\
\hline Technical & $118(69.4 \%)$ & $52(31.6 \%)$ & $170(55.6 \%)$ \\
\hline Manager & $10(66.7 \%)$ & $5(33.3 \%)$ & $15(4.9 \%)$ \\
\hline Supportive & $50(41.3 \%)$ & $71(58.7 \%)$ & $121(39.5 \%)$ \\
\hline \multicolumn{4}{|l|}{ Age } \\
\hline 20-29 years & $48(41.5 \%)$ & $34(58.5 \%)$ & $82(26.8 \%)$ \\
\hline $30-39$ years & $61(41.3 \%)$ & $43(58.7 \%)$ & $104(34 \%)$ \\
\hline $40-49$ years & $39(48.1 \%)$ & $42(51.9 \%)$ & $81(26.5 \%)$ \\
\hline$\geq 50$ years & $12(30.8 \%)$ & $27(69.2 \%)$ & $39(12.7 \%)$ \\
\hline
\end{tabular}

\subsubsection{Behavioural Factors of Civil Servants}

Out of 306 respondents, $273(89.2 \%)$ were never smokers, $246(80.4 \%)$ respondents were never chew khat; while 94.4\% were consumed fruit and vegetable 1-3 days per week and almost all respondents were prepared their food using vegetable oil. As to respondents level of physical activities, 207 (67.6\%) were undertaken moderate physical activities. Whereas $158(51.6 \%)$ respondents had problem related to physical, mental or social stress during their life (Table 2).

Table 2. Sex Adjusted Frequency Distribution of Behavioral Characteristic

\begin{tabular}{cccc}
\hline \multirow{2}{*}{ Variables } & \multicolumn{2}{c}{ Frequency } & Overall \\
\hline Smoking status & & Female=no(\%) & \\
never & $149(54.6 \%)$ & $124(45.4 \%)$ & $273(89.2 \%)$ \\
current & $11(73.3 \%)$ & $4(26.7 \%)$ & $15(4.9 \%)$ \\
Ex-smoker & $18(100 \%)$ & - & $18(5.9 \%)$ \\
never & & & \\
current & $61(50.8 \%)$ & $59(49.2 \%)$ & $120(39.2 \%)$ \\
Ex-drinker & $102(61.1 \%)$ & $65(38.9 \%)$ & $167(54.6 \%)$ \\
never & $15(78.9 \%)$ & $4(21.1 \%)$ & $19(6.2 \%)$ \\
current & & & \\
previous & $129(52.4 \%)$ & $117(47.6 \%)$ & $246(80.4 \%)$ \\
Khat use & $34(85 \%)$ & $6(15 \%)$ & $40(13.1 \%)$ \\
Good & $15(75 \%)$ & $5(25 \%)$ & $20(6.5 \%)$ \\
poor & $168(58.1 \%)$ & $121(41.9 \%)$ & $289(94.4 \%)$ \\
Fruit \&vegetable & $10(58.8 \%)$ & $7(41.2 \%)$ & $17(5.6 \%)$ \\
High & $6(75 \%)$ & $2(25 \%)$ & $8(2.6 \%)$ \\
Moderate & $123(59.4 \%)$ & $84(40.6 \%)$ & $207(67.6 \%)$ \\
inactive & $49(53.8 \%)$ & $42(46.2 \%)$ & $91(29.7 \%)$ \\
Yes & & & $158(51.6 \%)$ \\
No & $97(61.4 \%)$ & $61(38.6 \%)$ & $148(48.4 \%)$ \\
\hline Stress status & $81(54.7 \%)$ & $67(38.6 \%)$ &
\end{tabular}

\subsubsection{Bio-Medical Related Characteristics of Respondents}

Of 306 participants, $86(28.1 \%)$ participants had family history of hypertension and $49(16 \%)$ were enquired with family history of DM while 50(16.3\%) were overweight and $49(16 \%)$ were obese with the overall prevalence of obesity of $16 \%$. Overweight/obesity was slightly prevalent among females $47(36.7 \%)$ than males $52(29.2 \%)$. Abdominal obesity was more prevalent in female (59.9\%) than male. The mean body weight and waist circumference of the respondents were $68.5(\mathrm{SD}=11.2) \mathrm{Kg}$ and $88(\mathrm{SD}=12.75) \mathrm{Cm}$, respectively (Table 3). 
Table 3. Sex Adjusted Frequency Distribution of Bio- Medical Characteristic of Civil Servants Working in A/Minch Town, 2016

\begin{tabular}{|c|c|c|c|}
\hline \multirow{2}{*}{ Variables } & \multicolumn{2}{|c|}{$\begin{array}{l}\text { Frequency } \\
\end{array}$} & \multirow{2}{*}{ Overall } \\
\hline & Male $=$ no $(\%)$ & Female $=$ no $(\%)$ & \\
\hline \multicolumn{4}{|l|}{ BMI } \\
\hline normal & $126(60 \%)$ & $81(39.1 \%)$ & $207(67.6 \%)$ \\
\hline overweight & $25(50 \%)$ & $25(50 \%)$ & $50(16.3 \%)$ \\
\hline General obese & $27(55.1 \%)$ & $22(44.9 \%)$ & $49(16 \%)$ \\
\hline \multicolumn{4}{|l|}{ Abdominal obesity } \\
\hline Yes & $56(42.1 \%)$ & $77(59.9 \%)$ & $133(43.5 \%)$ \\
\hline No & $122(70.5 \%)$ & $51(29.5 \%)$ & $173(56.5 \%)$ \\
\hline \multicolumn{4}{|l|}{ Family history of HPT } \\
\hline Yes & $41(47.7 \%)$ & $45(53.3 \%)$ & $86(28.1 \%)$ \\
\hline No & $137(62.3 \%)$ & $83(37.7 \%)$ & $220(71.9 \%)$ \\
\hline \multicolumn{4}{|l|}{ Family history of DM } \\
\hline Yes & $22(44.9 \%)$ & $27(55.1 \%)$ & $49(16 \%)$ \\
\hline No & $156(60.7 \%)$ & $101(39.3 \%)$ & $257(84 \%)$ \\
\hline
\end{tabular}

\subsubsection{Distribution of Blood Pressure}

The mean SBP and DBP of participants were $120.87+14.15$ (121.78 SD 13.7 among men and 119.6 SD 14.7 among women) $\mathrm{mmHg}$ and $80.28 \pm 8.8$ (80.6 SD 8.4 among men and 79.6 SD 9.2 among women) $\mathrm{mmHg}$, respectively. The mean SBP and DBP of males were higher than females by $2.18 \mathrm{mmHg}$ and $1.00 \mathrm{mmHg}$, respectively. Both mean SBP and DBP rose steadily with age.

\subsection{Prevalence of Hypertension}

About 189 (61.8\%) participants had normal BP, 40 (13.1\%) were pre-hypertensive, 67 (21.9\%) hypertensive and $10(3.3 \%)$ were hypotensive up on blood pressure measurement. Eighty five $(27.8 \%)$ participants were hypertensive during and before survey. So that the overall prevalence of hypertension among the study participants were $27.8 \%(95 \% \mathrm{CI}=22.9-32.7)$ (Figure 1$)$.

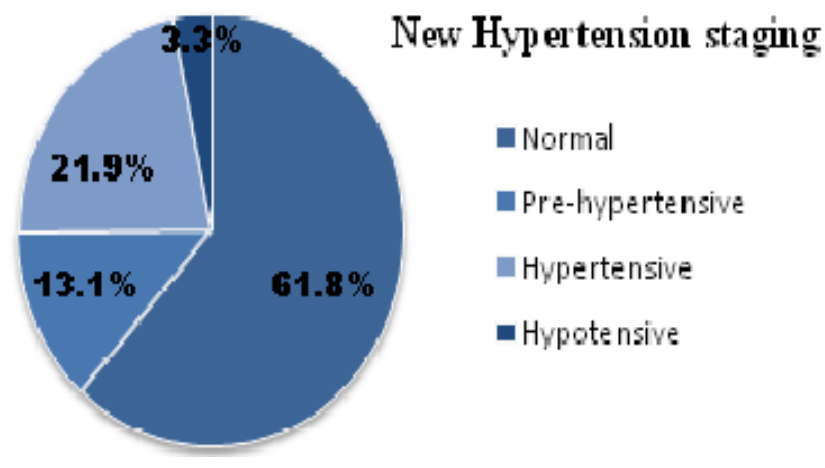

Figure 1. Hypertensive Staging of Civil Servants Working in Arba Minch Town, South Ethiopia

\subsection{Factors Associated with Hypertension}

Bi-variable analysis: The finding show that age was highly associated with hypertension $(\mathrm{p}<001)$ and Hypertension was significantly more prevalent in divorce than single and married $(\mathrm{p}=0.014)$. Likewise, the burden of hypertension was found more common among current smokers than never $(\mathrm{p}<0.001)$. The problem of hypertension was common among subject with past history of alcohol consumers than never ( $\mathrm{p}<0.001)$. Regarding to stress status of participants, subject who have stress related to living cost and work-overload were almost 9 time high risk of developed hypertension than without. Significantly higher proportion of hypertension was detected among subject who had family history of hypertension $(\mathrm{p}<0.001)$ and family history of DM $(\mathrm{p}<0.001)$. The risk of hypertension was about 14 time higher in subjects in those who had abdominal obesity $(\mathrm{p}<0.001)$.

Multivariate binary logistic regression: From Table 6, 13 variables with $p \leq 0.2$ were selected for the multivariate analysis. The final result of backward LR method of the analysis revealed that age, family history of hypertension, BMI, stress, WHR and alcohol consumption were predictors of hypertension (Table 4). 
Table 4. Bi-Variable and Multivariate Logistic Regression Analysis of Factors Associated with Hypertension among Study Participants in A/Minch Town ( $\mathrm{n=306),} 2016$

\begin{tabular}{|c|c|c|c|c|c|c|}
\hline \multirow{2}{*}{ Variable } & \multicolumn{2}{|c|}{ Hypertension } & \multicolumn{2}{|c|}{ Crude } & \multicolumn{2}{|c|}{ Adjusted } \\
\hline & Yes $(\mathrm{n} \%)$ & No $(\mathrm{n} \%)$ & $\mathrm{OR}(95 \% \mathrm{CI}$ & $\mathrm{P}$-value & $\mathrm{OR}(95 \% \mathrm{CI}$ & p-val \\
\hline Overall & $85(27.8 \%)$ & $221(72.2 \%)$ & - & - & - & - \\
\hline \multicolumn{7}{|l|}{ Sex } \\
\hline Male & $49(27.5 \%)$ & $129(72.5 \%)$ & 1 & & - & - \\
\hline Female & $36(28.1)$ & $92(71.9 \%)$ & $1.03(0.6-1.7)$ & 0.91 & -- & - \\
\hline \multicolumn{7}{|l|}{ Marital status } \\
\hline Single & $15(20.8 \%)$ & $57(79.2 \%)$ & 1 & - & - & \\
\hline Married & $64(28.6 \%)$ & $160(71.9 \%)$ & $1.5(0.8-2.9)$ & 0.2 & $0.8(0.24-3.2)$ & 0.8 \\
\hline Divorce & $6(60 \%)$ & $4(40 \%)$ & $5.7(1.4-22.8)$ & 0.014 & $0.6(0.5-7.9)$ & 0.7 \\
\hline \multicolumn{7}{|l|}{ Tobacco use } \\
\hline Never & $66(24.2 \%)$ & $207(75.8 \%)$ & 1 & & 1 & \\
\hline Current & $10(66.7 \%)$ & $5(33.3 \%)$ & $6.3(2-19)$ & 0.001 & $8.5(0.5-136)$ & 0.13 \\
\hline Ex-smoker & $9(50 \%)$ & $9(50 \%)$ & $2.79(1.1-7.3)$ & 0.036 & $1.9(0.4-8.5)$ & 0.39 \\
\hline \multicolumn{7}{|l|}{ Alcohol use } \\
\hline Never & $24(20 \%)$ & $96(80 \%)$ & 1 & & 1 & \\
\hline Current & $54(32.3 \%)$ & $113(67.7 \%)$ & $1.9(1.1-3.3)$ & 0.02 & $3.3(1.4-8)$ & 0.007 \\
\hline Ex-drinker & $7(36.8 \%)$ & $12(63.2 \%)$ & $2.3(0.8-6.6)$ & 0.11 & $8.9(1.9-42)$ & 0.006 \\
\hline \multicolumn{7}{|l|}{ Khat use } \\
\hline Never & $62(25.2 \%)$ & $184(74.8 \%)$ & 1 & & 1 & \\
\hline Current & $15(37.5 \%)$ & $25(62.5 \%)$ & $1.78(0.9-3.6)$ & 0.11 & $1.3(0.4-4.9)$ & 0.7 \\
\hline Previous & $8(40 \%)$ & $12(60 \%)$ & $1.98(0.8-5)$ & 0.16 & $1.1(0.2-6.2)$ & 0.87 \\
\hline \multicolumn{7}{|l|}{ Fruit \&vegetable } \\
\hline Good & $77(26.6 \%)$ & $212(73.4 \%)$ & 1 & & 1 & \\
\hline Poor & $8(47.1 \%)$ & $9(52.9 \%)$ & $2.4(0.9-6.6)$ & 0.07 & $3.0(0.6-15)$ & 0.2 \\
\hline \multicolumn{7}{|l|}{ Physic activities } \\
\hline High & $1(12.5 \%)$ & $7(87.5 \%)$ & 1 & & & \\
\hline Moderate & $51(24.6 \%)$ & $156(75.4 \%)$ & 2.3(0.3-19) & 0.4 & & \\
\hline Inactive & $33(36.3 \%)$ & $58(63.7 \%)$ & $3.98(0.5-37.8)$ & 0.21 & & \\
\hline \multicolumn{7}{|l|}{ Stress status } \\
\hline Yes & $72(45.6 \%)$ & $86(54.4 \%)$ & $8.7(4.5-16)$ & $<0.001$ & $12.3(4.9-30)$ & $<0.001$ \\
\hline No & $13(8.8 \%)$ & $135(91.2 \%)$ & 1 & & 1 & \\
\hline \multicolumn{7}{|l|}{ BMI } \\
\hline Normal & $36(17.4 \%)$ & $171(82.6 \%)$ & 1 & & 1 & \\
\hline Overweight & $18(36 \%)$ & $32(64 \%)$ & $2.7(1.4-5.3)$ & 0.005 & $0.98(0.35-2.8)$ & 0.97 \\
\hline Obese & $31(63.3 \%)$ & $18(36.7 \%)$ & $6.5(3.4-12)$ & $<0.001$ & $4.2(1.5-11.6)$ & 0.006 \\
\hline \multicolumn{7}{|c|}{ Abdominal obesity } \\
\hline Yes & $72(54.1 \%)$ & $61(45.9 \%)$ & $14.5(7.5-28)$ & $<0.001$ & $12.2(4.9-30.5)$ & $<0.001$ \\
\hline No & $13(7.5 \%)$ & $160(92.5 \%)$ & 1 & & 1 & \\
\hline \multicolumn{7}{|l|}{ Education } \\
\hline$<12$ grade & $7(24.1 \%)$ & $22(75.9 \%)$ & 1 & & 1 & - \\
\hline Certificate & $12(52.2 \%)$ & $11(47.8 \%)$ & $1.3(0.75-2.2)$ & 0.009 & $0.8(0.12-5.5)$ & 0.8 \\
\hline Diploma & $19(26.4 \%)$ & $53(73.6 \%)$ & $0.9(0.5-1.7)$ & 0.76 & - & - \\
\hline Degree & $47(25.8 \%)$ & $135(74.2 \%)$ & $0.79(0.48-1.3)$ & 0.36 & - & - \\
\hline \multicolumn{7}{|l|}{ FHHPT } \\
\hline Yes & $42(48.8 \%)$ & $44(51.2 \%)$ & $3.9(2.3-6.7)$ & $<0.001$ & $5.6(2.4-13)$ & $<0.001$ \\
\hline No & $43(19.5 \%)$ & $177(80.5 \%)$ & 1 & & 1 & \\
\hline \multicolumn{7}{|l|}{ FHDM } \\
\hline Yes & $24(49 \%)$ & $25(51 \%)$ & $3.1(1.6-5.79)$ & $<0.001$ & $2.5(0.8--7.6)$. & 0.11 \\
\hline No & $61(23.7 \%)$ & $196(76.3 \%)$ & 1 & & 1 & \\
\hline \multicolumn{7}{|l|}{ Age group } \\
\hline 20-29 year & $10(12.7 \%)$ & $72(87.8 \%)$ & 1 & & 1 & \\
\hline 30-39 year & $24(23.1 \%)$ & $80(76.9 \%)$ & $0.69(0.4-1.97)$ & 0.19 & $3.5(1.1-11)$ & 0.03 \\
\hline 40-49 year & $29(35.8 \%)$ & $52(64.2 \%)$ & $1.68(0.97-2.9)$ & 0.06 & $5.0(1.6-16)$ & 0.006 \\
\hline$>=50$ year & $22(56.4 \%)$ & $17(43.6 \%)$ & $4.2(2.1-8.38)$ & $<0.001$ & $13.3(3.6-49)$ & $<0.001$ \\
\hline
\end{tabular}

FHHPT $=$ family history of hypertension, FHDM = family history of diabetes mellitus

\subsection{Discussion}

Hypertension is becoming a major public health problem in Ethiopian civil servants working in government organization [12]. It is responsible for high burden of CVD and premature death and morbidity [7]. The present study show that, the prevalence of hypertension among civil servants working in Arba Minch town was $27.8 \%(95 \% \mathrm{CI}=22.9-32.7)$, which is comparable with other studies conducted in Addis Ababa minstery of civil servants (27.3\%), civil servants in Kaduna state of Nigeria (29\%), Gondar city (28.3\%), Bahir Dar (25.1\%) and Nigeria (27.1\%) [12], [14-17].

IJPHS Vol. 5, No. 4, December 2016 : $375-383$ 
The prevalence of hypertension in this study is considered to be higher as compared to other studies reports from southern Ethiopia of Durame (22\%) and sidama (10.1\%), community based study done in North Ethiopia (18.1\%), Southwest Ethiopia (13.2\%) and Vietnam (14\%) [9-10], [18-20]. This discrepancy may be due to the fact that most of these studies were done both in urban and rural dwellers whereas our study was brought about in urban dwellers. The other reason might be due to study population and age difference i.e. in the southwest study, the study population was those who came for health care service in the hospitals and the other four studies were conducted in general population.

However, the result of this study was lower than that of finding from India (44.8\%), Senegal (46\%), Ghana (42.4\%), South Africa (46\%) and Angola public sector workers (45.2\%) [21-24]. The reason for this discrepancy might be associated with the fact that difference in socio-economic and socio-cultural status, racial and genetic play role.

Although the mean SBP and DBP of female were lower than males, females have higher prevalence of hypertension but the difference was statistically non-significant. An increased in the prevalence of hypertension associated with age has been detected in this study, which is consistent with many other studies [25-26]. In this study, as many studies agreed, the risk of hypertension increased with age. Study participants older than 50 years and 40-49 years were 13.3 and 5.0 times, respectively more likely to be hypertensive than those who were belonging to 20-29 years of age. This could be due to age related vascular change and atherosclerosis.

History of current and previous alcohol consumption were identified as predictor of hypertension in this study. Current and previous alcohol user were $3.3(\mathrm{p}=0.007)$ and $8.9(\mathrm{p}=0.006)$ times, respectively more likely to be hypertensive than nonusers. The possible reason for this might be due to immediate and cumulative effect of alcohol on cardiac output and blood vessels respectively. The finding was comparable with similar study done in Ethiopia [10], [27].

Physical inactivity was not a significant risk factor as expected in this study which is comparable with study done in Addis Ababa civil servants [12]. This is due to the fact that, the measurement of physical activity relied on participants reported estimation of time spends on various activities and hence subjective measures of intensity by different participants. This may have resulted in misclassification of intensity and duration of physical activities.

BMI and WHR are used for classification of general obesity and abdominal obesity. WHR is more sensitive in detecting hypertension than BMI [28]. In this study both high BMI and WHR were associated with hypertension. Accordingly, the likelihood of hypertension among general and central obese participants was 4.2 and 12.2 times, respectively more prone to hypertension than the normal one. This might be due to the fact that excess accumulation of fat result in increasing blood cholesterol and triglyceride level and lower high-density lipoprotein levels. This finding was consistent with other study conducted in Ethiopia and Senegal [14], [18], [23].

Family history of hypertension was considered to be a potential genetic risk factor of hypertension. This study demonstrated the association of hypertension with family history of hypertension. Those who had family history of hypertension were $5.6(95 \% \mathrm{CI}=2.4-13 \%)$ times more likely to be hypertension than counterpart. The finding was in line with other studies conducted in Gondar Ethiopia and Africa [14], [29]. The possible reasons might be due to the fact that participants with family history of hypertension have the same genetic component and environmental factor that family tend to share the same lifestyle choice and behavior.

Stress level of study participants is one of the most important psycho-social predictor of hypertension. Stress increase the heart rate and blood requirement and can raise blood pressure over a period of time, and precipitate heart attack and stroke [30]. In this institution based study, stress status of study participants were strong predictors of hypertension. An individual with psycho-social stress were 12.3 times high risk of developing hypertension than counterpart.

Unlike many other study findings [22], [31-33], this study did not revealed any association of hypertension with sex, marital status, education, tobacco use, khat use, dietary fruit and vegetable intake, physical activities, knowledge, perception family history of DM and salt consumption. This might be illustrated by dynamics related to study population, setting, sample size and socio-economic and cultural difference.

Even though this study has come up with important finding with respect to hypertension in work place, there are certain limitations worth mentioning here. Due to cross- sectional nature of the study temporal relationship could not be ascertained, it did not include biochemical component which could have an effect on hypertension, social desirability, misclassification and recall biased are also there. The other concern was issue of generalizability of the finding to the whole population, since this study was institution based. However, it can be applicable to similar population or urban working population in the country. 


\section{CONCLUSION AND RECOMMENDATION}

The prevalence of hypertension among civil servants working in Arba Minch town was found to be high. A large proportion (78.8\%) of subject with hypertension was unaware of their condition. Concerning to factors associated with hypertension, age, abdominal obesity, psycho-social stress and family history of hypertension were strong predictors of hypertension among civil servants working in Arba Minch town. Similarly general obesity, current and ex-drinker of alcohol were other predictors of hypertension.

The findings confirm the growing public health challenge of hypertension and associated factors as a public health problem in this particular population. Based on the findings of the study the following recommendations are forwarded. Hypertension should be regarded as a disease of public health importance in this particular community. Hence, there should be an indication for institution based hypertension screening and work place wellness programs. Provision of conducive working environment and reducing obesity through exercise needs due attention; further studies regarding risk factors assessment of hypertension by inclusion of biochemical factors and objective measuring is also important.

\section{ACKNOWLEDGEMENTS}

The authors would like to sincerely thank Head of the sectors, data collectors and study participants who ever contributed for this work. We would also like to acknowledge Arba Minch University, College of Medicine and Health Sciences for facilitating the study.

\section{REFERENCES}

[1] V. L. Robert, et al., "Heart Disease and Stroke Statistics-2012 update: A Report from the American Heart association," Circulation, vol/issue: 125(1), pp. e2-e220, 2012.

[2] WHO, "A Global Brief on Hypertension. A Venue Appia, Geneva Switzerland," WHO, 2013.

[3] WHO, "Report on prevention of Chronic Diseases: A Vital investment. Geneva Switzerland,” WHO, 2008.

[4] L. Sherlock, et al., "Hypertension among older adult in Low-and Middle income countries: Prevalence, awareness and control," Int .J. Epidemiology, 2014.

[5] Dalal S., et al., "Non communicable disease in sub-Saharan African: what we know now," International J. Epidemiology, vol/issue: 40(1), pp. 885-901.

[6] Hendriks M. E., et al., "Hypertension in sub-Saharan Africa: Cross sectional surveys in four urban and rural communities," PLOS ONE, vol/issue: 7(3), 2012.

[7] WHO, "Global info base indicators, blood pressure raised in Ethiopia. Geneva, Switzerland," WHO, 2011.

[8] Abebe S. M., et al., "Prevalence and associated factors of Hypertension: A Cross sectional Community Based Study in North West Ethiopia," PLOS ONE, vol/issue: 10(4), 2015.

[9] Helelo T. P., et al., "Prevalence and associated factors of Hypertension among Adults in Durame Town, Southern Ethiopia," PLOS ONE, vol/issue: 9(11), 2014.

[10] Giday A. and Tadesse B., "Prevalence and determinants of Hypertension in rural and urban area of Southern Ethiopia," EthiopMed, vol/issue: 49(2), pp. 139-147, 2011.

[11] Tesfaye F., "Epidemiology of CVD risk factors in Ethiopia: the rural-urban gradient," J. Human Hypertension, vol/issue: 21(2), pp. 28-37, 2007.

[12] Angaw K., et al., "Prevalence of hypertension among federal ministry of civil servants in Addis Ababa, Ethiopia: a call for a workplace- screening program," BMC cardiovascular disorder, vol. 15, pp. 76, 2015.

[13] WHO, "STEP wise approach to surveillance (STEPS)," Geneva, World Health Organization.

[14] Awoke, et al., "Prevalence \& associated factors of hypertension among adults in Gondar, northwest Ethiopia: a community based cross sectional study," BMC cardiovascular disorder, vol. 12, pp. 113, 2012.

[15] Anteneh Z., et al., "Prevalence and correlation of hypertension among adult population in Bahir Dar city, northwest Ethiopia," Inter. J Gen Med, vol. 8, pp. 175-185, 2015.

[16] Abisola M., et al., "Prevalence and associated factor with hypertension and obesity among civil servants in Kaduna state," Pan Afri Med J., vol/issue: 18(1), pp. 13, 2014.

[17] Biliaminu S., et al., "Prevalence of hypertension and associated variable in paid worker in llorin, Nigeria," PubMed, vol/issue: 11(4), pp. 342-6, 2008.

[18] Mengistu M., "Pattern of BP distribution and prevalence of hypertension and pre-hypertension among adults in Northern Ethiopia: disclosing the hidden burden," BMC, vol. 14, pp. 33, 2014.

[19] Gudina E. K., et al., "Prevalence of hypertension and its risk factors in southwest Ethiopia. Dave press Journal: Integ Blood Press," Control, vol. 6, pp. 11, 2013.

[20] Van H., et al., "Gender difference in the prevalence and socio-economic determinants of hypertension: finding from the WHO STEPS surveys in rural community of Vietnam," J Hum. Hypertension, vol/issue: 20(2), pp. 109-115, 2006.

[21] Chaturvedi S., et al., "Hypertension in Delhi: prevalence, awareness, treatment and control," Trop Doct, vol/issue: 37(3), pp. 142, 2007.

[22] Daniel C. and Pedro M., "Prevalence of cardiovascular risk factors and socio-economic level among public sector worker in Angola," BMC Public health, vol. 13, pp. 732, 2013. 
[23] Pessinabas, et al., "Prevalence and determinants of hypertension and associated factors: Data from a populationbased cross sectional survey in Saint Louis, Senegal," Cardiovascular J Afr., vol. 24, pp. 180, 2013.

[24] Gebreselassie K. Z. and Podyab M., "Epidemiology of hypertension stage in two countries in sub Saharan Africa: Factors associated with hypertension stages," Int J Hyper, 2014. Article ID 959256.

[25] Martin P., "Chronic Non Communicable Disease in Ethiopia- A hidden burden. Ethiopian," J. Health Science, vol/issue: 22(2), pp. 1-2, 2012.

[26] Okpechi I. G., et al., "BP gradients and cardiovascular risk factors in urban and rural populations in Abia state south eastern Nigeria using the WHO Stepwise approach," PLOS ONE, vol. 8, pp. e73403, 2013.

[27] Sisay T., et al., "Prevalence of tobacco consumption, alcohol, kchat use and high blood pressure among adult I Jimma town, southwest Ethiopia," Science J of public health, vol/issue: 3(5), pp. 650-654, 2015.

[28] Gandhi R., et al., "The relation between BMI and WHR in knee osteoarthritis," can J Surg, vol/issue: 53(3), pp. 151-154, 2010.

[29] Tesfaye F., et al., "Association between BMI and BP a cross three population in Africa and Asia," J Hum. Hypertension, vol. 21, pp. 28, 2007.

[30] Laurel M., et al., "Prevalence of hypertension in rural and urban population in Kenya," Journal of public health, vol. 317, pp. 1347-1349, 2006.

[31] Tesfaye F., et al., "Association of smoking and khat(Catha eduli Forsk) use with High Blood Pressure among adults in Addis Ababa, Ethiopia," Center of Disease Control and prevention, 2008.

[32] Habiba R., et al., "Hypertension among Tunisian adults: a result of TAHINA Project Jap," Soc Hypertension, vol. 35, pp. 341, 2012.

[33] Bayray A. and Berheh, "Nutritional status and major risk factors of hypertension among adult in tigray, north Ethiopia: case-control study,” Int J Pharma science Res, vol/issue: 3(11), pp. 4206-12, 2011. 